\section{ORIGITAT COmmUNTCATIONS.}

\section{INFLUENCE OF NOXIOUS EFFLUVIA ON THE ORIGIN AND PROPAGATION OF EPIDEMIC DISEASES.}

By I. D. GRIIN(iER, Fiqq, Lecturer on l'hysiology at St. Thomus's Hospital.

(Concluded from 1. 100 of last number.)

II. INFLEexce OF EFFLUVIA ARISING FROM PRIVIES AND CESSPOOLS.

Ir is the remark of an acute observer, that one of the best tests of the progress which a people have made in civilization, is furnished by the manner in which they dispose of their excreta. That this observation has a foundation in truth, is amply shown; independently of what we see going on around us, by the accounts received from India and other semi-civilized countries. Often as the evils arising from the cesspool system have been foreed on the public attention, I feel assured that they are still but most imperfectly alprehended. Some glimmerings of the truth have indeed hroken into the diurkness: we do not now-a-days hear many of the ancient eulogiums on cow-stalls, horse-dung, and similar remedics, once popular, and not, as 1 know, yet extinct. The painful experience of the present winter has likewise convincel the higher classes in many parts of the provinces, that they are not exempt from the dangers of the poisonous effluvia which dicily decimate the poor in their nealected abodes. Owing to the increased attention now paid to sanitary inquiries, and the warnings of our own profession, the public are beginning to comprehend that much of the ailing and sickness and diarrhou, to which children, especially in large towns, are suhject, and which are often attributed to "bilious attacks", are in reality dependent on the malaria arising from cesspools and foul drains. Another and more willely diffused error is, that lecause no odour or stench can be perceived, no injurious effluvia can be present: but it is important to point out that poisonous gases may be present in quautities quite sufficient to injure the health, and yet without affecting the senses. I had a curious groof of this a few years agro, when in puiring into the disinfecting properties of the nitrate of lead. On visiting the Fever Ilospital, the wards were found to be, as they always arc, scrupulously clean, and perfectly devoid of sincli. The day of the inonth was written on one of the walls with the colourless liyuid; and, on examining the writing next day, the letters had lecome evident by their liark colour, owing to the presence in the air of sulphuretted hydrogren, and the consequent formation of sulphuret of lead.

The effluvia from ccsspools, when concentrated, afford a marked illustration of the principle already noticed, that any one of the predisposing causes of epidemic disease is capalle, according to circumstances, of developing all the principal members of the class: lut the extended inquiries of late years have shown, that affections of the abdominal organs are specially liable to be thus induced. Gastric fever, of a low character, and often of the remittent type, vomiting, diarrhceil, dysentery, and cholera, are the constant results of what may be termed the privy "itmosphere. There is no point on which there is a more unanimous agreement among the practitioners in populous districts, than on this; or on which I have received more full and precise evidence. Among other indications, I may mention that, in various parts of the kinglom, it has been noticed that the families in courts and alleys who live immediately opposite to or over privies, suffer much more from the epidemics just specified, than those more remotely located. In unses in this prosition often hecome so notorious as the habitation of fever, diarrboa, cholera, etc., that the people avoid them; and from this cause alone, I have frequently seen such dwellings tenantless. That the same cause operates, and in the same manner, wherever it is present, was abundantly proved during the cholera epidemic.
On these points I have lately obtained a largo body of exset information. In the city of Norwich, it is a common custom, even in the most respectable houses, to have large cesspools in the cellar or basement, frequently of enormous size, some of them being 60,80, and 100 feet deep. The effluvia were often most overpowering; and in every instance in which an inquiry was made, I found that the inmates, and especially the children, who always suffer more than adults, had laboured under romiting, diarrhoea, low remitting fever, etc., which were attributed by the medical attendants to the malaria thus arising. The correctness of this opinion has been lately confirmed in a most satisfactory manner. The local authorities, acting under the Public Health Act, have, in a large number of instances, removed the cesspool, and substituted a cleanly water-closet for the filthy privy; and in all the cases where I instituted inquiries, it was found that the bealth of the inmates had improved in a marked degrec, and especially that the gastric and febrile disturbance had ceased.

A similar instance of the evil and the remedy, but on a smaller scale, was mentioned to me by my friend. Mr. Collett, of Worthing, to whom I am indehted for the following details, the like of which might be adduced in a multitude of other examples. Mr. Collett says :- "From 1838 to 1842, I was in constant attendance on the families of the Coast Guard station, who occupied ten houses, each containing four rooms; the inmates averaging six in each dwelling. These people were in very comfortable circumstances, the men earning from $18 \mathrm{~s}$. to $24 \mathrm{~s}$. per week. These details are given to show that destitution could not have existed. These families were attacked with remittent and typhus fever; and it is important to remark, that the women and children, who were more or less at home during the day, and of course at night, were the principal sufferers, and to such an extent, that, in almost every house, one or more of the inmatcs were frequently under medical treatment: the men, who were much from home, for the most part escaped." On seeking for the cause of this obstinate and localised attack, Mr. Collett satisfied himself that this proceeded from an open ditch without any outlet, into which the privies empticd their contents, situate at the rear of the houses, and emitting, of course, offensive effuvia. After great difficulty, he succeeded in having the ditch properly drained, covered over, and provided with an outlet. Some low, marshy ground, hetween the houses and the sea, was also drained. A period of nine years has elapsed; and, although epidemics, principally attributable to similar local causes, have occhisionally prevailed, the buildings in question have altogether escaped, and no persons can be more healthy than their inhabitants.

The escape of the men in this case, owing to their absence from home, reminds me of a similar cxemption, but on a much larger scale, which occurred at Bcrlin, during the cholera of 1848 . A body of 6,000 men, artisans and labourers of all classes, and residing in different parts of the city, were employed in the open country in some public works: they were absent from home fifteen or sixteen hours daily, only returning to sleep at night. These men were so remarkaily excmpt from cholera, only eight of the whole number being attacked, as to attract general attention; and the only explanation that could be given was, that they were for nearly two-thirds of the twenty-four hours withdrawn from their crowded homes; while their families, remaining, suffered in the same degree as the inhabitants in general.

During the late unprecedented season, sereral towns, as well as rural districts, have been attacked most severely with low fever, which, in all the cases I have inquired into, has been more or less of the gastric type, and attended with diarrhnea. That the effluvia from cesspools and drains have been, in addition to the cxcessive moisture and high temperature, the more immediate predisposing cause of this epidemic, is the decided opinion of all the practitioners in those towns which I have officially visited. One peculiarity which has attracted very general attention, is, that the higher classes and tradespeople have suffered severely-not, 
on the whole, however, more than the poor, although that has been asserted.

With the view of illustrating the subject under consideration, I propose to describe the attack which occurred in the months of November and December, among the higher ranks at a bathing-place on the south-western coast; and this selection is made, because, so far as could be ascertained, there was but one predominating cause to which the outbreak could be attributed. It must be premised, that in the above town, there is no system whatever of sewerage; the water-closets and privies having nothing but cesspools to receive their contents. Many of the first families were attacked, two or more of the inmates sometimes suffering; and several deaths occurred in some of the principal terraces and streets, where the rent and taxes of unfurnished houses were often as high as $£ 60, £ 80$, and $£ 100$ a year. Owing to the excessive rain, and the absence of deep drainage, many of the houses, villas, etc., had become flooded in the basement floor, the consequences of which may be gathered from the description of a newly erected terrace, where I was taken by a physician in large practice. In the basement, which was entirely undrained, were placed the kitchens, and at the back, and on the same level, was the servants' privy, and the cesspool of the water closet. All this was flooded; the water had risen as high as the sent of the privy; the cesspool had overtlowed; the soil had consequently been washed into the kitchens, causing a horrible effurium. This had taken place very generally elsewhere and the nuisance thus caused was so great, that the medical attendants could distinguish by the smell, on first entering, when the house was flooded. In one of the first-rate houses which I examined, and where the gentleman had suffered from fever, the stench from the drains leading to the cesspools was so overpowering, that the whole house was filled with it whenever the plug, which had becn applied to pen in the poisonous gases, was withdrawn. In the course of the inquiry, I visited several houses of this class, where there had been fever; and in every case the privy eftluvium was intense, and was assigned as the cause of the attack. The same marked influence of these cmanations was noticed among the principal families at a town in South Wales, the whole subsoil of which is so soaked with cesspool matter, that in the best parts of the town, foul percolation has taken place into the wells, to such an extent, that maggots have been found in the water. Whenever there is much rain, regurgitation occurs; the drains and cesspools overtlow, filling the houses with effluvia, to which both the sufferers themselves and their medical attendants attributed the gastric fever which prevailed at the time of my visit.

The instances now adduced plainly show, that wherever humau beings, whether poor or rich, are exposed to the privy atmosphere for a sufficient time, and in sufficient intensity, their health inevitably suffers, from a degree which may amount only to what is called "ailing", to nausen, dyspepsia, and diarrhoa; or to low fever, usually of the gastric type, often remittent; to obstinate and fatal diarrhoea and dysentery ; or, when present, to cholera.

But it would be taking a very imperfect view of the influence of this deleterious agent, to suppose it only induces gastric derangement and fever: the whole system suffers, and pre-eminently in children, those delicate tests of preventible disease. As one of the more elucidative instances of such affections, and indeed of the whole subject, I may perhaps be pernitted to quote the case of Christ Church Workhouse, belonging to the Whitechapel Union, although it is already recorded in my report on cholera.* In this establishment, 400 children were lodged; and, separated from it by a narrow lane, was a manufactory of artificial manure, where night-soil and putrid blood were desiccated, causing a horrible effluvium in the workhouse, and inducing a large amount of diarrhoca. During the cholera, two out breaks of diarrhcea were directly traced to these effluvia, each following the renewal of the manufactory, which had

- Report of the General Board of Health on Epidemic Cholera, 1849. ndix B, p. 88. for a time been checked by legal preceedings. But, bo sides this, Mr. Byles, to whom I am Indebted for these particulars, states that, whenever the wind blew from the works, fever of an intractable and typhoid form prevailed; and that measles, small-pox, and other infantile diseases, assumed a typhoid tendency. He also states-and to this point I would call special attention-that a most unmanageable and fatal form of aphthre of the mouth and genitals, running rapidly into gangrene, was so prevalent, that, in one quarter of the year, twelve infants died from it. These attacks were referred by Mr. Byles to the poisonous efluvia; and that he was correct in his opinion, was proved by the fact, that when, after repeated attempts to remore this monster nuisance, and after many lives had been sacrificed, the manufactory was finally closed, the health of the whole establishment was so greatly improved that, up to the date of the report, not a single death occurred among the children, except from chronic disease. I hare recently been informed by the medical officer of the town in Wales to which I have alluded, that he has found the same gangrenous disease in infants, in filthy and overcrowded houses.

\section{SANITARY IMPROVHMENTS.}

After the consideration of so many painful topics, the question suggests itself-Is all this evil, this misery, this degradation, necessary? Is it a condition of our existence that these desolating fevers-these exhausting diseases, which sicken and destroy the infant just entering upon life, and sap and undermine the vigour of manhood,- should arise, and persist, notwithstanding all efforts for their removal? The answer to this all-important query is to be found in the definition of the predisposing causes of epidemic disease. Poisonous effluvia, polluted water, putrid food, are without : they exist accidentally, and form no necessary part of man's nature. We now know precisely how they are generated, and how they act, and we perceive how they may be removed. It is indeed remarkable, that any doubt ever should have existed in intelligent minds on the sulject; for it is obvious that the inquiry is infinitely more simple than wany of the problems presented by morbid affections, arising from internal causes, The phenomena are palpable-gross, they might be termed - both physically and metaphysically ; their causes are patent, and force themselves on the most ordinary entrauce to knowledge-the senses ; the consequences are more constant, direct, and definite than usually present themselres in any recondite investigation. Causes, conditions, and results are known; what clse is requisite for a scientific and successful research? It has, in fine, become evident to all who are familiar with the process of inductive knowledge, that the whole question is ripe for solution. In this communication, allusion has been made to the ignorance, and conseguent incertitude, that have prevailed in regard to this subject ; but in the interests of humanity, and in rindication of that exalted science which it is our happiness and privilege to profess, it must be declared that among the physicians and surgeons personally acquainted with the discases of the poor, not as they are studied in the wards of a hospital, hut as they are revealed in fotid courts and stinking houses, there never has been any doubt. Dr. Ferrier, when, on entering a close and crowded room, he, to bring relief to the victim of ferer, thrust his cane through the window, has typified the whole category of sanitary evils and sanitary remedies. I have myself scen, within the last three months, two instances essentially the same, where the medical attendants had actually had holes cut in the walls of houses with no outlet at the back, in order to admit fresh air to typhus patients. Let the public, then, know that medical science, even from the remotest ages, bas pronounced its decision.

As we are speaking of opinions, reference may be made to one which indicates some strange obliquity, and which has always suggested to my mind the painful truth that, in our fallen estate, we love darkness rather than light. Medical men, when they advocate measures calculated to promote the public health are often suspected, and have in 
2 thousand instances been directly charged with sinister motives. It much concerns the common weal, that the public should comprehend that this is their question, not ours; nay, it is the very reverse; for, in promoting efficient sanitary reforms, the medical practitioner labours to secure that which, if attained, must, as no one foresees so clearly as himself, involve a sacrifice of his pecuniary interest. To the worldly minded, such a disinterested spring to action is not only incredible, but incomprehensible ; and, therefore, they reject it as a thing impossible. True it is that such lofty motives are not natural to men : they have their origin in purer sources-in the liberal studies that refine and elevate the mind-in the communion held with God, through the observation of His works-and above all, in the spiritualising influences of the Gospel of peace, which, while it declares it to be more blessed to givo than to receive, commands us to look on the things of others rather than on our own.

Having been led to touch upon this topic, I would offer some homage, demanded by truth, to this elevated spirit of sclf-sacrifice. From the office which I have had the honour to hold, constant opportunities have been presented to me of witnessing the generous and uncalculating zcal with which, in the midst of every kind of discouragement, often coming from the most powerful and influential quarters, the members of our common profession, in all parts of the kingdom, have initiated and supported the leyislative measure designed to secure the public health. Well and nobly have they fulfilled their mission! But it may be objected, that I am myself a medical man. Such undoubtedly is my high privilege. Let, then, other and, as it may be called, more disinterested witnesses speak. In the course of the preliminary inquiries prescribed by the Public IIealth Act, more than two hundred towns have been examined by the engineering inspectors of the General Board of Health. Those gentlemen have been brought into immediate contact with all classes and all callings; and knowing well their sentiments, I may, without entering into invidious personalities, say that the disinterested spirit displayed, and the all-important support rendered, by the whole body of our profession, has inspired them with esteem and admiration.

But let us return to the more immediate object before usthe question of sanitary improvement. In the course of this paper, several marked instances have been incidentally noticed, in which the removal of the assigned cause of sickness was followed by improved health ; and equally striking evidence will be found in the excellent reports of my valued friend and colleague, Dr. Sutherland. If time permitted, I could adduce example upon example, proving equally on the largest and the smallest scale, that every really effectual improvement has been followed by a diminution or eradication of zymotic, and even of other diseases; for it could be abundantly shown, that the benefit is never restricted to the former class, though it is there more marked. A workhouse has been drained, flagged, and ventilated; the health of the inmates has immediately improved, and they, though previously suffering from fever, diarrhoea, and so on, have thenceforward been greatly or entirely exempt from these diseases. A new and lofty ward, well ventilated, has been substituted for an old and close one, as at St. Thomas's and other hospitals. What has followed? The diminution of erysipelas-the hospital test of a foul atmosphere-so marked, as to have attracted the notice of the medical officers. A foul labyrinth of unpaved, wet, and filthy courts has been flagged, dried, and cleansed, as in a part of Newcastle-on-Tyne, called Sandgate; and there ensues so great and permanent a reduction, that it is capable of being reduced to figures, and expressed per centum, as in the case of St. Olave's, Southwark, and elsewhere. A large ship, ventilated by the skill of an Arnott, transports to the antipodes 1000 convicts, soldiers, and sailors, and only one old man dies on the passage; whilst an emigrant ship, unventilated and néglected, is decimated in crossing the Atlantic. Again, a lunatic asylum or a prison is properly and efficiently provided with sanitary arrangements, and in the midst of a great and sweeping epidemic, like that of cholera in 1849, their inmates escape, one and all.

In some instances of this kind, it has lately been said that the new system has failed; and even that epidemics, from which the old establishment was free, have, as the consequence, sprung up in the new. I have had occasion to inquire officially into some of these alleged cases of failure, and it has been shown to the satisfaction of important public bodies, who had entertained the above opinion, that the occurrence of the sickness was traceable, not to the principles of sanitary improvement, but to defects in construction, or mistaken plans; nay, in some cases the rery efficiency of one part of the arrangements has, owing to fundamental errors, exasperated the mischief. No one, for example, would deny that it is a great amelioration to substitute in a crowded court, or in the cellar of a house, a cleanly watercloset for a foul privy ; but it does not therefore follow, that it would be equally desirable, if at all, to place a water-closet in the cell of a jail, within six feet of the head of the bed, and where the prisoner spends twenty-two out of the twenty-four hours. An efficient ventilating apparatus for public establishments, such as I have seen, is of vast importance if in right relation to all parts of the buildings; but if it is misplaced in regard to water-closets or drains, it may, as I have found, by the very force of suction which is its merit, poison the atmosphere, by drawing the foul air out of the soil-pipe or of the common sewer; and this notwithstanding the supposed defence of syphon or other water-traps. But besides these more obvious sources of failure, there are others more subtle and general, and, thereforc, more important, which altogether escape the notice of those engaged professionally in sanitary works ; for instance, every plumber and engineer ought to know thoroughly the great principle of the diffusion of gases, as it is immediately concerned with the efficient action of all water-traps.

In glancing at the results of sanitary improvements, it is interesting and important to consider the results that have followed the introduction of the model lodging-houses. These institutions afford a kind of evidence which is of special value, inasmuch as the great object of their philanthropic founders was to test the value of sanitary improvement; and further, because the information derived from them is exact, numerical, and trustworthy. It is probably known to the majority of this audience, that these houses are situated in all parts of the metropolis, and several of them in the centre of the most unhealthy districts, as St. Giles and Drury Lane, where every form of zymotic disease prevails, and from which fever is never absent. They are occupicd by the labouring classes; and although, in some of those for families, the tenants belong to a superior class of artisans, in others, especially those for single men, persons following the humblest occupations, as itinerant sellers of articles in the streets, are lodged by the week.

The following details are taken from the official reports which I have had occasion to make on the subject :-

"In May 1851, I personally examined seren out of the eight existing establishments. The inhabitants (concerning whose health I instituted a searching inquiry) then amounted to 1,507, of whom 726 were children-a class most susceptible of zymotic disease. There had been only one case of typhus from the commencement ; and yet one of the institutions, with 5:50 inmates, had been opened three years and a half. At the time of the cholera, the population of these houses amounted to 795 ; and yet there was only one case of cholera, whilst among the population of London generally, including all classes, one person in every 151 died, and about one in every 75 was attacked.

"The statistics of the Metropolitan Buildings, Old Pancras Road, are peculiarly instructive, inasmuch as they have been now open nearly five years, and contain a fixed population, of whom many are labourers and mechanics. Up to May 31, 1851, the yearly mortality had been somewhat more than two per cent. of the inmates, which is about the 
ang artality of Fingland.* I have lately agme as the arerage mortin this establishment; and the results are even again visited this establing nineteen months, up to Octomore remarkable ; for during ninetion of 640 , there have been ber 1852 , with an average population of 640 , there have been only thirteen deaths, being 1.2 per cent. per annum, or at the rate of only 12 in the thousand. In another establishment for families, in Albert Street, Spitalfields, with about 30 c inhabitants, the mortality during the last eighteen 300 inhabitants, the mortality dun even that in the Pancras Road institution. The rate of mortality in England and Road institution. The rate of at present is $2 \cdot 2$ per cent., or 22 in the thousand; in the metrorolis it is $2 \cdot 39$, or nearly 24 in the thousand ; in Lirerpool it is $\mathbf{3 \cdot 4 3}$, or upwards of 34 in the thousand; while in the part of Surrey not included in the metropolis, it is 1.72 , or 17 in the thousand.

"But properly to estimate these facts, it must be stated that the number of children, which, if considerable, always raises the mortality, in the Metropolitan Buildings considerably excecds the proportion in London gencrally ; in 1851, ably excecds the proportion $62 \cdot 3$ per cent. of the total inmates; and yet the mortality among them was only $2 . \overline{5}$ per cent. ; whilst in the metropolis, in 1841, the number of children under ten years of age was $21 \cdot 7$ per cent. of the whole population, and the mortality was 5.2 per cent., or nearly double that of these model houses. The experience of the last nineteen months still shows the same exemption from ferer as in the earlier years, not one death having occurred from that cause; nor was there any death from small-pox or scarlet fever. Two cases of small-pox occurred among the adults, both of which recovered ; and it is interesting to observe that the disease did not spread, not a single child having been attacked. Whenever, on the contrary, a casc of small-pox occurs in the crowded habitations of the poor, and especially in the common lodging-houses, it is notorious to medical officers that it spreads rapidly among the sickly and predisposed population around. I recently had occasion to inspect a court at Gloucester, containing twenty-two families, and about 110 individuals, and where in two months there had been thirtcen cases and three deaths from small-pox."

This paper will, it is hoped, assist in placing in a clearer point of view two of the most general and intluential agents which concur in lowering the health of the swarming population of our suburban districts. The proofs, too, derived from so many sources, demonstrating the possibility of destroying one of the two conditions on which the development of epidemic disease depends, will not, I trust, be unacceptable to those who are interested in that which, in regard to the physical well-being of the people, is the great question of the present times. And if we, who form a part of the more favoured classes of society, escape the miseries and sorrows of our humbler brethren, let us never forget that it is due rather to the fortuitous march of events than to any inherent superiority which we are entitled to claim as our own. The foul abode, the unwashed body, the reeking excrements by which thousands of our industrious countrymen are surrounded, inflicting a penalty from which the brute, in virtue of its instinct, is mercifully protectedthese, and an untold number of the like afflictions, might, but for the goodness of Gol, have been our own lot; nay, worse, the fate of our wives and of our children. It might, but for the accident of birth, have been ours to see those nearest and dearest to us pining, sickening, and dying, before our eyes, the victims of a pestilential atmosphere, from which, though recognised, there was no escape; thus adding to the bitterness of death the consciousness that it was thus caused, and was no necessary part of the primeval curse. It might have been our fate to feel the very springs of life and energy giving way in the midst of manhood, and when a young and helpless family depended on the vigour and capacity for labour which constitute the poor man's only fortune. To those who are ignorant of the scenes daily en-

- Report on the present state of certain parts of the Metropolis. and on the Model Lodging Houses of London. By R. D. Grainger, Esq., p. 29. acted in the crowded and foul abodes of the populous dis tricts of England, and even in the very centre of the metropolis, this language may bear the semblance of exaggerated sentimentality; but I have, by a long and painful gerat bo words can express, ture can realize, the misery to which large masses of the ture can realize, the misery to which large mass presant mo existence of evils which are moment subject, owing to the existence of evils which attributable to the unprecedented increase of our manufacturing towns, but which must in no crease of our manufacturing towns, but wat neglect, out of which, after a lapse of centuries, we are now beginning to awake.

Highgute, February 1853.

\section{ON PY.EMIA.}

By JOSEPH SAMPSON GAMGFF, Fisq., House-Surgeon to University Collerge Hospital.

(Read before the Medical Society of University College, Nov. 25th, 185\%.)

A corscioussess of the vastness and intricacy of the subject on which $I$ have undertaken to submit to you a few reflections, and a feeling of my own inability to do it justice, constrains me to appeal to your indulgence; an appeal, the special need of which will at once be perceived, when I confess that I do not intend this communication to be a mere compilation of the ideas of authors on the subject of Pyæmia. The great discrenancies between them render it obvious that they are not all right; and my own clinical observations in thirteen cases force me strongly to suspect, that in many very important points the great majority of them are far from the truth. Thus believing, I should deem it most just to myself, and most consistent with my duty, to relate the histories of my cases, to analyse them, and then to point out in what respects my own observations agree with, or differ from the teaching of the day. But to carry this plan into execution, copious as my notes of cuses are, a series of addresses, and not a single one, would be required; and hence I am forced to abandon it for another more expedient, though to me less congenial, and I fear to others less efficient scheme. Under existing circuustances, I must confine myself to presenting a sketch of the present state of knowledge among surgeons, especially awong English surgeons, on the subject of my thesis, and to giving a succinct account of the disease. In so doing, it shall be my special study to adduce from my note-book of cases as much evidence in support of my statements and of my criticism on accepted opinions, as time will permit.

Anxious as I am to be brief, I cannot abstain from making a few preliminary remarks.

Such is the present state and rate of progress of pathological science in general, but especially of surgical pathology, that even in the humblest of inquiring minds, a zealous desire to do somewhat to contribute to its advancement cannot but be awakened. If this be true in general, how true is it in this particular instance. Let any one look on a poor creature first seized with the pyæmic shiver: the violent shake of the whole body, the drawn and haggard features, the din and sunken eye, the earthy look, the mental depression, the succeeding intense heat and profuse sweating, will at once indicate to him that something serious has happened. A succession of these attacks, the supervention of diarrhoea, and mental aberration, not unfrequently in a few hours hurl a previously stout and healthy man into eternity. Let the witness of this scene bear in mind that, but a very few years since, this disease was unknown; that there are very strong grounds for believing that it is among the most frequent of surgical diseases, and yields to none of them, if it do not exceed them all, in its fatality ; that at the present day, to my certain knowledge, surgeons of eminence have shewn themselves ignorant of typical cases of this disease brought under their observation; that in the most recent systems of surgery, strong presumptive evidence 